Morahan, G. (2012), Insights into type 1 diabetes provided by genetic analyses. Current Opinion in Endocrinology, Diabetes and Obesity, 19(4), 263-270.DOI:

http://dx.doi.org/10.1097/MED.0b013e328355b7fe

Copyright: (C) 2012 Lippincott Williams \& Wilkins, Inc.

This is the authors' accepted manuscript version of an article accepted for publication in Current Opinion in Endocrinology, Diabetes and Obesity following peer review. The published version is available at the journal home page of the publisher, Lippincott Williams \& Wilkins, Inc.

This version was made available in the UWA Research Repository on 1 August 2013 in compliance with the publisher's policies on archiving in institutional repositories.

Use of the article is subject to copyright law in respect of the copyright owner. Readers may download, print, and save electronic copies of whole works for non-commercial use only. Any other use requires the permission of the copyright owner. 


\title{
INSIGHTS INTO TYPE 1 DIABETES PROVIDED BY GENETIC
}

\section{ANALYSES}

\author{
Grant Morahan \\ Centre for Diabetes Research, \\ The Western Australian Institute for Medical Research, \\ Centre for Medical Research, University of Western Australia
}

Contact:

Grant Morahan,

MRF Building Level 6

50 Murray St

Perth WA 6000

Australia

gem@,waimr.uwa.edu.au,

$+61-8-92240206$

Funding:

The author's work is supported by Program Grants 53000400 and 37612600 from the National Health and Medical Research Council of Australia, by the Diabetes Research Foundation (WA) and by grant 1DP3DK085678-01 from the National Institute of Diabetes and Digestive and Kidney Diseases. 


\section{Structured Abstract}

Purpose of review: Recent identification of over sixty loci contributing to the susceptibility of developing Type 1 diabetes (T1D) provides a timely opportunity to assess what is currently known of the genetics of T1D, and what these discoveries may tell us about the disease itself. Recent findings: The major findings will be discussed under five main themes: T1D risk gene identification; molecular mechanisms of susceptibility; shared genetic aetiology with other diseases; development of novel analytical methods; and understanding disease heterogeneity.

Summary: The plethora of T1D risk genes that have been identified risk overwhelming clinicians with lists of gene names and symbols that have little bearing on management, and provide a challenge for researchers to place the genetics T1D in a more amenable clinical context.

Keywords: type 1 diabetes, genetics, complex genetic diseases, disease heterogeneity

\section{INTRODUCTION}

The hallmark of type 1 diabetes (T1D) is its origin due to autoimmune processes that destroy the insulin-producing beta cells. It would therefore be expected that the genes predisposing an individual to risk of developing T1D would be different from those which confer risk of type 2 diabetes, which does not have an autoimmune basis. It should also be expected that there would be some overlap in the genetic risk factors between T1D and other autoimmune diseases. Over the last few years, improved technology has enabled discovery of genes for many diseases, not least T1D. These discoveries have confirmed the above predictions. However, much still remains to be discovered. This review will summarize gene discoveries made over the past year, as well as discussing how these genes may contribute to disease. Given the wellknown and well-characterized association of HLA genes with T1D risk, recent reviews of which may be found in refs 1 and 2, more emphasis will be given here to the non-HLA genes. 
The recent findings on T1D genetics indicate several emerging themes: known genetic associations have been followed up and replicated in additional populations; new T1D risk genes have been identified; characterization of candidate genes indicate molecular pathways of disease and commonalities with other autoimmune disease; existing resources, notably from the Type 1 Diabetes Genetics Consortium [T1DGC; 3-5] and the Wellcome Trust Case Control Consortium [WTCCC; 6], have been leveraged to generate new methods and discoveries; and, despite its heterogeneity and the large number of susceptibility genes identified, there seems to be distinct clinical subtypes of T1D. In this review, recent reports in the field of T1D genetics will be discussed in relation to these themes.

\section{Confirmation Of Previously Reported T1D Risk Genes}

It is important that genetic findings can be replicated in independent cohorts of cases. For the purposes of this discussion, the largest single GWAS conducted on T1D [4] will be taken as the canonical study. Readers may refer to this paper and recent reviews [1,2] for references to earlier reports of individual associations of genetic polymorphisms with T1D. Table 1 lists the genes that were found to be associated with T1D in that study, and which have been replicated in the last year in additional cohorts or with new methods.

The replications of these genes fall into two categories: those involving genome-wide analyses and very large new cohorts, including via meta-analysis [7-9], and those testing particular variants in smaller locally recruited samples [10-14]. Bradfield et al. [7] conducted a large meta-analysis with a combined total of 9,934 cases and over 16,000 controls. They estimated they had up to three times the power of the previous largest GWAS for detecting loci of small effect [7]. Their analyses confirmed 43 of 49 previously reported loci. Cooper et al. [8] replicated 37 of the 42 susceptibility loci they tested, finding consistent direction of effects and with combined $P \leq 0.001$; the remaining five loci were significant in cases but not in sib-pair families (ZFP36L1, UBASH3A, C1QTNF6 and GAB3) or vice-versa (CCR7). Reddy et al. [9] 
tested 21 loci, confirming 18 of these in their smaller cohort of locally-recruited cases and controls.

In targeted studies of individual loci, Keene et al. [11] examined the association signal on chromosome 12q23, near the $E R B B 3$ gene. By re-sequencing an $80-\mathrm{kb}$ region they found over 100 new single nucleotide polymorphisms (SNPs). Genotyping a total of 42 SNPs spanning over $200 \mathrm{~kb}$, they found 15 had significant T1D association, with two providing separate evidence for association. One was located in an exon of ERBB3, while the other novel SNP was in an intergenic region. Espino-Paisan et al. [12] also found evidence for association with 2 separate SNPs in the $12 \mathrm{q} 23$ region in their analysis of Spanish T1D cases. Thus, this region appears to make an unusually complicated contribution to T1D susceptibility.

Another complicated locus is $I L 2 R A$, encoding the receptor for the cytokine IL-2. Again, multiple SNPs appear to make independent contributions to susceptibility [4]. Fichna et al. [10] analysed Polish cases and controls, replicating association with 2 of the four SNPs they studied. Other replications published recently include the R262W variant in the $S H 2 B 3$ gene [13] and of PTPN2 [15] in Russian and Spanish T1D cases, respectively. In contrast to the high throughput genotyping used in many studies, Di Stasio et al. [23] found blue eyes was a significant predictor of T1D in an Italian sample, confirming a previous report from Northern Europe.

\section{New T1D Risk Genes: When is enough enough?}

Despite over fifty loci previously found to have significant association with T1D, more risk factors are still being identified. Table 1 also lists new genes reported as being associated with T1D since January 2011. Many of these genes were found using either new analytical methods or by examining particular candidate genes. 
By virtue of the increased power of their GWAS meta-analysis cohort, Bradfield et al. [7] found two new loci and possibly a third. The novel loci were defined by a SNP in the LMO7 gene on chromosome $13 \mathrm{q} 22$ and another in a intergenic region of chromosome 6q27 with a $900 \mathrm{~kb}$ associated interval which is relatively gene-rich. The third SNP tagged a region of linkage disequilibrium [LD] extending over $800 \mathrm{~kb}$ from $25.5 \mathrm{Mb}$ on chromosome $2 \mathrm{p}$; this region may overlap with a locus previously implicated by SNP rs 2165738 at $24.5 \mathrm{Mb}$ [4].

The major histocompatibility complex exerts the highest genetic contribution to T1D susceptibility $[1,2]$ and is likely to harbour additional risk genes in addition to the well-known HLA class II genes. Baschal et al. [17] followed up a signal at the telomeric end of the MHC they had studied previously. They accounted for effects of HLA by logistic regression, mapping a high-risk haplotype to a $20 \mathrm{~kb}$ region containing an uncharacterised gene. Using novel algorithms for phasing the multi-allelic HLA genotypes and for partitioning HLA strata in conditional testing to analyse WTCCC and T1DGC data, Cheung et al. [18] found eight novel SNP associations around $31.3 \mathrm{Mb}$ on $\mathrm{chr} 6$, in a LD region containing TCF 19, POU5F1, CCHCR 1 and PSORSIC1 as potential candidates. Forbes et al. presented a range of data, including functional studies on subjects from the FinnDiane study and on the NOD mouse, to link SNPs in the gene encoding the receptor for advanced glycation end-products (RAGE) with a decline in circulating soluble RAGE levels around the onset of T1D [19].

A number of studies of candidate genes reported significant association at the SLC11A1, IKZF1 and FUT2 loci $[16,20,22]$. Bitti et al. [21] found evidence for association with a polymorphism in codon 72 of TRP53 in an Italian cohort; this is close to the rs $16956936 \mathrm{SNP}$ tagging the DNAH2 region [4] and must be replicated in larger cohorts. 


\section{Genetic overlap of T1D with other diseases of immune dysregulation}

It is to be expected that genes which lead to dysregulation of immune responses could be associated with many diseases which have either an autoimmune basis or some other breakdown of appropriate regulation. Accordingly, other diseases with a similar response should show association with T1D risk genes, and vice versa. Together with epidemiological and clinical evidence, this rationale is supported by previous genetic studies as well as reports published in the past year [24-25]. For example, in the largest study almost half of the 107 SNPs tested were associated with at least one of seven related diseases [24].

Wagner et al. applied the same rationale to define factors causing occurrence of multiple autoimmune diseases [26]. Drawing on the T1DGC dataset, they found that related autoimmune diseases were more likely to be found in females having a family history of related diseases, later onset of T1D, and increased antibodies to glutamic acid decarboxylase (GAD).

A clear example of using genetics to resolve clinical conditions was provided by Gan et al. who tested a variant in the gene encoding the lymphocyte surface marker Cd226 in cases of Addison's Disease or autoimmune polyendocrinopathy type 2 [27]. Their findings suggested that there was no association with isolated Addison's Disease and that any association with these diseases was by virtue of the underlying association with $\mathrm{T} 1 \mathrm{D}$, providing a means to define patient subtypes in these conditions.

\section{Functional characterization of T1D risk alleles}

Gene identification is the important first step on the road to understanding the molecular basis of disease. Perhaps the best detailed investigation of T1D risk alleles recently was by Davison et al. [28] who studied the T1D associated SNP in an intron of CLEC16A. They found that a nearby gene, $D E X 1$, was a more likely candidate for T1D susceptibility than CLEC16A, because the relevant DNA variant affected expression of DEX1. They showed a physical 
interaction of the CLEC16A intron with the promoter of DEX1 but not with the CLEC16A promoter [28]. This study highlights the important point that the best candidate gene is not necessarily the one closest to the most associated SNP.

CTLA4 was one of the earliest non-HLA T1D risk genes identified. Gerold et al. [29] investigated the role of the soluble form of CTLA4, whose RNA splice variant is lower from the susceptibility allele. Transgenic NOD mice engineered so as to not produce this splice variant showed accelerated T1D onset [29].

The contribution of known risk factors to T1D via apoptosis of beta cells was investigated: Santin et al. [30] demonstrated a role for PTPN2 interacting with cell-death molecules. Chen et al. [31] showed a protective mitochondrial variant could protect against beta cell death and diabetes in mouse models.

Systems genetics analyses integrate gene expression and higher order traits with underlying genetic variation, and is a powerful method for investigating transcriptome-wide effects of DNA variants. Rotival et al. [32] used this approach to demonstrate two of the T1D SNPs affected gene expression of other genes both as cis and trans regulators. Berchtold et al. [33] undertook a similar approach at the proteomic level to identify Huntingtin-interacting protein 14 as a strong candidate. It was found to be required for glucose-stimulated insulin release and promoted $\beta$-cell survival via anti-apoptotic effects. Vandiedonck et al. [34] conducted a detailed investigation of gene expression across the major histocompatibility complex, finding that many haplotype-specific differences in gene expression and frequent alternative splicing.

\section{Using T1D GWAS data to develop new genetic methods}

The wealth of data generated by the T1DGC and WTCCC has enabled development of new analytical methods and strategies. It is beyond the scope of this review to discuss these 
individually, but note that they make advances in three main areas: enhanced discovery of the causative SNPs in T1D genes [14, 35-38]; detecting rare variant associations [39, 40]; and disease risk prediction [41, 42]. For example, Huang et al. [14] found new association signals by increasing the density of the marker map and using haplotypes. They used information from the 1000 Genomes Project to impute genotypes in the WTCCC cohort. Their approach was validated by "discovering" loci [near IL2RA and SH2B3] that had been overlooked by the original WTCCC study but were found subsequently. They further refined the SH2B3associated signal to a SNP near the $C U X 2$ gene.

\section{Heterogeneity}

On one hand, the disease known as type 1 diabetes is easy to diagnose and, despite heterogeneity including a wide age of onset, it is generally regarded as a single disease. On the other hand, with over 60 loci now known to contribute to its risk, and doubtless with more to be uncovered, it could be considered as incredibly heterogeneous in a genetic sense: essentially, each person affected by T1D [except identical twins] would have a unique combination of genotypes at all these risk alleles. The implication is that each person may have a different molecular genetic pathway to disease. The truth probably lies between these extremes, so we could consider what recent evidence there are for discrete T1D disease subtypes.

Heterogeneity of T1D is perhaps most apparent in age at onset, autoantibody production, and associated autoimmune diseases. In turn, these traits can also show differences according to HLA genotypes. Earlier genetic linkage studies did show differences in linkage to non-HLA genes according to factors such as HLA status, autoantibody status, disease onset and gender [eg ref 43 which mapped the IDDM13 locus that is now confirmed via association with SLC11A1 [16]]. It is reasonable to suggest that the first level of heterogeneity may be 
determined by genotype at HLA class II genes, which then drives association with other HLAlinked genes, non-HLA genes, and ultimately the clinical traits mentioned.

The availability of over 4,000 affected sib-pair families recruited and characterized by the T1DGC allowed a comprehensive study of the effect of stratification on genetic linkage [5]. Consistent with earlier studies [eg 43], certain loci did show increased evidence of linkage following stratification, although no locus apart from HLA showed as strong linkage as expected based on the large numbers of families available. While this may be due to inclusion of families from countries having wide ethnic and environmental differences, the study nevertheless supported the notion that T1D is a heterogeneous disease, caused by interaction of different HLA haplotypes with an apparently random combination of alleles from the constellation of non-HLA risk genes [5].

Nevertheless, certain association of alleles at HLA and other loci may be found: as mentioned above, new loci within or near the HLA complex have been implicated by stratifying on HLA status $[17,18]$. In addition, it would be expected that some risk genes would be more likely to bring about an earlier onset, and this was reported for PTPN2, TRP53, and IFIH1 [15, 21, 44]. Slower progression to disease would suggest slower loss of residual beta cell function, and this was demonstrated in a study of the PTPN22 risk variant [45]. Adult-onset of T1D represents the extreme of the age at diagnosis trait, but an extensive study of a German cohort of found few differences compared to pediatric-onset cases; it was concluded that a lower overall genetic load was thought to slow the progression to clinical T1D [46].

A primary role of HLA is in presentation of antigen to $\mathrm{T}$ cells, so it would be expected that a key correlate of heterogeneity would be that different antigens would be recognized by the immune system according to HLA genotype. Brorsson et al. [47] found correlation between HLA-DQB1*0302 and autoantibody specificity for the ZnT8 Arg325Trp isoforms; they also 
found that early onset $[<5 \mathrm{y}]$ cases had lower titres of antibodies to ZNT8 and GAD. Howson et al. reported similar results: more antibodies in older onset cases, while specificity of autoantibodies showed differences in association with different HLA genes: GAD and insulinoma-associated antigen-2 antibodies had the strongest association with HLA-DRB1 while GAD antibody levels were associated with -DQB1 alleles [48]. Tying autoantibody status with underlying physiology, Cubas-Duenas et al. found that GAD antibodies were more frequently found in subjects who showed insulin resistance [49]. In contrast, IA2 antibodies were not accompanied by insulin resistance, but tended to be produced by subjects with detectable circulating enterovirus RNA [49]. These results suggest heterogeneity in T1D cases brought about by interplay between different environmental and genetic factors.

\section{Conclusion}

The array of over 60 genes now associated with T1D susceptibility presents a bewildering challenge for the non-geneticist. How can all these genes be taken into account when considering a child's risk status? Do all or any of these genes have any bearing on disease management? As noted above, it is difficult to determine how any one gene may impact on a disease pathway if there really is independent association of a subset of SNPs from a collection of sixty or more, interacting with at least 3 different high risk HLA genotypes. Worse, there seems no compelling reason for clinicians to learn an exhausting list of genes and SNPs if these have no impact on clinical management. The challenge for geneticists seems not to derive longer lists with more and more genes of smaller and smaller impact, but to construct a framework that both simplifies and integrates what we currently know into an easily understood and clinically relevant model. 


\section{Key Points}

- The genetics of Type 1 diabetes is very complex, with over 60 genes now identified as contributing to its risk;

- Many of these genes also contribute to related diseases;

- Systems genetics and conventional approaches are required to understand the molecular basis by which these genes contribute to disease;

- The resources and data assembled for these studies support further modelling and refinement;

- A challenge for researchers is to find ways in which the genetic data will be helpful to clinicians in understanding and managing the disease.

\section{Acknowledgements}

The author's work is supported by Program Grants 53000400 and 37612600 from the National Health and Medical Research Council of Australia, by the Diabetes Research Foundation (WA) and by grant 1DP3DK085678-01 from the National Institute of Diabetes and Digestive and Kidney Diseases.

\section{References}

1. Morahan G, Varney M. The Genetics of Type 1 Diabetes. The HLA Complex in Biology and Medicine. A Resource Book” JayPee Brothers Publishing, New Delhi, 2010; Chapter 12, pp $205-218$.

*2. Noble JA, Erlich HA Genetics of type 1 diabetes Cold Spring Harb Perspect Med 2012; 2 a007732.

A recent review of T1D genetics, with emphasis on the HLA genes. 
3. Rich SS, Akolkar B, Concannon P, Erlich H, Hilner JE, Julier C, Morahan G, Nerup J, Nierras C, Pociot F and Todd, JA Overview of the Type 1 Diabetes Genetics Consortium. Genes Immun. 2009; 10: S1-S4.

4. Barrett JC, Clayton DG, Concannon P, Akolkar B, Cooper JD, Erlich HA, Julier C, Morahan G, Nerup J, Nierras C, Plagnol V, Pociot F, Schuilenburg H, Smyth DJ, Stevens H, Todd JA, Walker NM, Rich SS and the Type 1 Diabetes Genetics Consortium Genome-wide association study and meta-analysis find that over 40 loci affect risk of type 1 diabetes. Nat Genet. 2009; 41: 703-707.

**5. Morahan G, Mehta, M, James, I, Chen, WM, Akolkar B, Erlich HA, Hilner JE, Julier C, Nerup J, Nierras C, Pociot F, Todd JA, Rich SS and the Type 1 Diabetes Genetics Consortium (2011) Tests For Genetic Interactions in Type 1 Diabetes: Linkage and Stratification Analyses of 4,422 Affected Sib-Pairs. Diabetes 60:1030-40.

This paper describes the largest genetic linkage study for any disease and found that apart from HLA and INS there was little evidence for important susceptibility factors discoverable by linkage methods, and that T1D susceptibility was caused by actions of HLA and an apparently random selection from a large number of modest effect loci.

6. Wellcome Trust Case Control Consortium. (2007) Genome-wide association study of 14,000 cases of seven common diseases and 3,000 shared controls. Nature. 2007; 447:661-78.

**7. Bradfield JP, Qu HQ, Wang K, Zhang H, Sleiman PM, Kim CE, Mentch FD, Qiu H, Glessner JT, Thomas KA, Frackelton EC, Chiavacci RM, Imielinski M, Monos DS, Pandey R, Bakay M, Grant SF, Polychronakos C, Hakonarson H. A genome-wide meta-analysis of six type 1 diabetes cohorts identifies multiple associated loci. PLoS Genet. 2011 7:e1002293.

This report describes a large study, including meta-analysis, that confirms previously reported genes and discovered three new genes. 
**8. Cooper JD, Howson JM, Smyth D, Walker NM, Stevens H, Yang JH, She JX, Eisenbarth GS, Rewers M, Todd JA, Akolkar B, Concannon P, Erlich HA, Julier C, Morahan G, Nerup J, Nierras C, Pociot F, Rich SS; the Type 1 Diabetes Genetics Consortium. Confirmation of novel type 1 diabetes risk loci in families. Diabetologia. 2012 55:996-1000.

This paper explicitly tested 18 novel genes from the T1DGC GWAS (ref 4) in a study of over 7,000 families, confirming these genes and the previous results were not due to population stratification.

*9. Reddy MV, Wang H, Liu S, Bode B, Reed JC, Steed RD, Anderson SW, Steed L, Hopkins D, She JX. Association between type 1 diabetes and GWAS SNPs in the southeast US Caucasian population. Genes Immun. 2011;12:208-12.

This study also provided independent confirmation of many of the previously-reported T1D GWAS risk genes.

*10. Fichna M, Zurawek M, Fichna P, Januszkiewicz D, Nowak J. Polymorphic variants of the $I L 2 R A$ gene and susceptibility to type 1 diabetes in the Polish population. Tissue Antigens. 2012; 79:198-203.

Confirms previous reports of independent associations of genetic variants at the gene encoding the receptor for interleukin-2, which can drive $\mathrm{T}$ lymphocyte proliferation and may allow expansion of autoreactive $\mathrm{T}$ cells.

*11. Keene KL, Quinlan AR, Hou X, Hall IM, Mychaleckyj JC, Onengut-Gumuscu S, Concannon P. Evidence for two independent associations with type 1 diabetes at the $12 \mathrm{q} 13$ locus. Genes Immun. 2012; 13:66-70.

An intensive study including resequencing in an $80 \mathrm{~kb}$ region and analyzing variants spanning more than $200 \mathrm{~kb}$ flanking an original association signal showing the complex contribution to T1D by this locus. 
*12. Espino-Paisan L, de la Calle H, Fernández-Arquero M, Figueredo MA, de la Concha EG, Urcelay E, Santiago JL Polymorphisms in chromosome region 12q13 and their influence on age at onset of type 1 diabetes. Diabetologia. 2011; 54:2033-7.

This study also confirmed the 12q13 contribution to T1D risk in a Spanish cohort, with the risk genotypes contributing to earlier age at diagnosis.

*13. Lavrikova EY, Nikitin AG, Kuraeva TL, Peterkova VA, Tsitlidze NM, Chistiakov DA, Nosikov VV. The carriage of the type 1 diabetes-associated R262W variant of human $L N K$ correlates with increased proliferation of peripheral blood monocytes in diabetic patients. Pediatr Diabetes. 2011; 12:127-32.

This gene, more commonly known as $S H 2 B 3$, was confirmed in Russian cases, and the susceptibility allele was shown to be associated with increased lymphocyte proliferation.

*14. Huang J, Ellinghaus D, Franke A, Howie B, Li Y. 1000 Genomes-based imputation identifies novel and refined associations for the Wellcome Trust Case Control Consortium phase 1 Data. Eur J Hum Genet. 2012 doi: 10.1038/ejhg.2012.3.

Leveraging two rich data sources can lead to better definition of disease genes, as described by these authors.

15. Espino-Paisan L, de la Calle H, Fernández-Arquero M, Figueredo MA, de la Concha EG, Urcelay E. A polymorphism in PTPN2 gene is associated with an earlier onset of type 1 diabetes. Immunogenetics. 2011; 63:255-8

*16. Yang JH, Downes K, Howson JM, Nutland S et al. Evidence of association with type 1 diabetes in the SLC11A1 gene region. BMC Med Genet. 2011;12:59.

Testing a candidate gene for the IDDM13 locus [cf 42] significant associations were found with variants in the $S L C 11 A 1$ (formerly known as NRAMP) gene.

*17. Baschal EE, Sarkar SA, Boyle TA, Siebert JC, Jasinski JM, Grabek KR, Armstrong TK, Babu SR, Fain PR, Steck AK, Rewers MJ, Eisenbarth GS Replication and further 
characterization of a Type 1 diabetes-associated locus at the telomeric end of the major histocompatibility complex. J Diabetes. 2011; 3:238-47.

Further work by this group localizing a susceptibility gene at the telomeric end of the major histocompatibility complex.

*18. Cheung YH, Watkinson J, Anastassiou D. Conditional meta-analysis stratifying on detailed HLA genotypes identifies a novel type 1 diabetes locus around TCF19 in the MHC. Hum Genet. 2011; 129:161-76.

This study used new algorithms to parse T1DGC and WTCCC HLA data, identifying new candidate genes within the major histocompatibility complex.

**19. Forbes JM, Söderlund J, Yap FY, Knip M, Andrikopoulos S, Ilonen J, Simell O, Veijola R, Sourris KC, Coughlan MT, Forsblom C, Slattery R, Grey ST, Wessman M, Yamamoto H, Bierhaus A, Cooper ME, Groop P. Receptor for advanced glycation end-products (RAGE) provides a link between genetic susceptibility and environmental factors in type 1 diabetes. Diabetologia. 2011; 54:1032-42.

The authors showed that circulating RAGE levels were associated with genetic variants in its gene and declined at the time of onset of autoantibody production. An AGE-lowering treatment prevented diabetes in the NOD model.

20. Swafford AD, Howson JM, Davison LJ, Wallace C et al. An allele of IKZF1 (Ikaros) conferring susceptibility to childhood acute lymphoblastic leukemia protects against type 1 diabetes Diabetes. 2011; 60:1041-4.

*21. Bitti ML, Saccucci P, Capasso F, Piccinini S, Angelini F, Rapini N, Porcari M, Arcano S, Petrelli A, Del Duca E, Bottini E, Gloria-Bottini F Genotypes of p53 codon 72 correlate with age at onset of type 1 diabetes in a sex-specific manner. J Pediatr Endocrinol Metab. 2011;24:437-9. 
Though a small study by contemporary standards, the authors found association with a strong candidate gene which should be followed up in a larger cohort.

*22. Smyth DJ, Cooper JD, Howson JM, Clarke P, et al. FUT2 nonsecretor status links type 1 diabetes susceptibility and resistance to infection. Diabetes. 2011; 60:3081-4.

Another candidate gene study finding evidence for a role in T1D for a gene that determines blood group secretor status and was reported to provide susceptibility to Crohn's disease.

23. Di Stasio E, Maggi D, Berardesca E, Marulli GC, Bizzarri C, Lauria A, Portuesi R, Cavallo MG, Costantino F, Buzzetti R, Astorri E, Pitocco D, Songini M, Pozzilli P; IMDIAB Group. Blue eyes as a risk factor for type 1 diabetes. Diabetes Metab Res Rev. 2011; 27:609-13.

**24. Cotsapas C, Voight BF, Rossin E, Lage K, Neale BM, Wallace C, Abecasis GR, Barrett JC, Behrens T, Cho J, De Jager PL, Elder JT, Graham RR, Gregersen P, Klareskog L, Siminovitch KA, van Heel DA, Wijmenga C, Worthington J, Todd JA, Hafler DA, Rich SS, Daly MJ; FOCiS Network of Consortia. Pervasive sharing of genetic effects in autoimmune disease. PLoS Genet. 2011; 7:e1002254.

Meta-analyses of multiple autoimmune diseases revealed nearly half of 107 genetic variants showed association with multiple diseases. The authors also reported that SNPs which predispose to the same subsets of diseases were near genes encoding distinct groups of interacting proteins.

25. Zhebrun D, Kudryashova Y, Babenko A, Maslyansky A, Kunitskaya N, Popcova D, Klushina A, Grineva E, Kostareva A, Shlyakhto E Association of PTPN22 1858T/T genotype with type 1 diabetes, Graves' disease but not with rheumatoid arthritis in Russian population. Aging. 2011; 3:368-73.

*26. Wägner AM, Santana A, Herńndez M, Wiebe JC, Nóvoa J, Mauricio D; Type 1 Diabetes Genetics Consortium. Predictors of associated autoimmune diseases in families with type 1 diabetes: results from the T1DGC. Diabetes Metab Res Rev. 2011; 27:493-8. 
Analysing over 3,200 families, the authors report on characteristics shared by cases having related diseases in addition to T1D.

*27. Gan EH, Mitchell AL, Macarthur K, Pearce SH. The role of a nonsynonymous CD226 (DNAX-accessory molecule-1) variant (Gly 307Ser) in isolated Addison's disease and autoimmune polyendocrinopathy type 2 pathogenesis. Clin Endocrinol (Oxf). 2011; 75:165-8. This paper describes a genetic analysis that distinguishes subtypes of diseases that can overlap with T1D.

**28. Davison LJ Wallace C, Cooper JD et al. Long-range DNA looping and gene expression analyses identify DEXI as an autoimmune disease candidate. Hum Mol Genet. 2012 Jan $15 ; 21: 322-33$.

Detailed molecular investigation revealed that the most likely SNP contributing to T1D acted by influencing gene expression of a nearby gene, rather than that of the gene in which it was situated. This is an important finding because it shows that finding the "real" T1D genes is likely to be much more difficult than previously expected.

*29. Gerold KD, Zheng P, Rainbow DB, Zernecke A, Wicker LS, Kissler S. The soluble CTLA-4 splice variant protects from type 1 diabetes and potentiates regulatory T-cell function. Diabetes. 2011; 60:1955-63.

The authors find lower levels of RNA encoding soluble CTLA4 accompany the susceptibility allele, and show that NOD mice genetically engineered to produce less sCTLA4 have accelerated T1D.

*30. Santin I, Moore F, Colli ML, Gurzov EN, Marselli L, Marchetti P, Eizirik DL. PTPN2, a candidate gene for type 1 diabetes, modulates pancreatic $\beta$-cell apoptosis via regulation of the BH3-only protein Bim. Diabetes. 2011; 60:3279-88.

Most of the known T1D genes are involved in the immune system; this paper reports a possible role for a T1D gene in cell death of beta cells. 
31. Chen J, Gusdon AM, Mathews CE. Role of genetics in resistance to type 1 diabetes. Diabetes Metab Res Rev. 2011; 27:849-53

**32. Rotival, M, Zeller T, Wild PS et al. Integrating genome-wide genetic variations and monocyte expression data reveals trans-regulated gene modules in humans. PLoS Genet. 2011; 7:e1002367.

The authors used systems genetics analyses to reveal how T1D risk variants could affect expression of genes nearby and on other chromosomes.

**33. Berchtold LA, Størling ZM, Ortis F, Lage K, et al. Huntingtin-interacting protein 14 is a type 1 diabetes candidate protein regulating insulin secretion and beta-cell apoptosis. Proc Natl Acad Sci U S A. 2011 Sep 13;108:E681-8.

Using a method for predicting protein that could interact with products of genes associated with T1D susceptibility, these authors identified a novel candidate. Modulation of levels of Huntingtin-interacting protein 14 in beta cells affected sensitivity to apoptosis mediated by proinflammatory cytokines.

**34. Vandiedonck C, Taylor MS, Lockstone HE, Plant K, et al. Pervasive haplotypic variation in the spliceo-transcriptome of the human major histocompatibility complex. Genome Res. $2011 ; 21: 1042-54$

Detailed analysis of gene expression across the MHC revealed both differential expression between HLA haplotypes and a high frequency of splice variants.

Systems genetics and proteomic analyses revealed a surprising protein that could contribute to beta cell death and diabetes.

*35. Lehne B, Lewis CM, Schlitt T. Exome localization of complex disease association signals. BMC Genomics. 2011 Feb 1;12:92.

This paper anticipates how detailed exome sequencing can help disease gene discovery. 
36. Kostem E, Lozano JA, Eskin E Increasing power of genome-wide association studies by collecting additional single-nucleotide polymorphisms. Genetics 2011; 188:449-60.

37. Lewis SN, Nsoesie E, Weeks C, Qiao D, Zhang L. Prediction of disease and phenotype associations from genome-wide association studies. PLoS One. 2011;6:e27175

38. Lehne B, Lewis CM, Schlitt T. From SNPs to genes: disease association at the gene level. PLoS One. 2011;6:e20133.

39. Feng T, Elston RC, Zhu X Detecting rare and common variants for complex traits: sibpair and odds ratio weighted sum statistics (SPWSS, ORWSS). Genet Epidemiol. 2011; 35:398409.

40. Browning SR, Thompson EA. Detecting Rare Variant Associations by Identity by Descent Mapping in Case-control Studies. Genetics. 2012 10.1534/genetics.111.136937

*41. Lee SH, Wray NR, Goddard ME, Visscher PM. Estimating missing heritability for disease from genome-wide association studies. Am J Hum Genet. 2011; 88:294-305.

The issue of missing heritability was addressed for T1D using WTCCC data.

42. Roshan U, Chikkagoudar S, Wei Z, Wang K, Hakonarson H. Ranking causal variants and associated regions in genome-wide association studies by the support vector machine and random forest. Nucleic Acids Res. 2011; 39:e62.

43. Morahan G, Huang D, Tait BD, Colman PG, Harrison LC. Markers on distal chromosome 2q linked to insulin-dependent diabetes mellitus. Science 1996; 272:1811-3.

*44. Winkler C, Lauber C, Adler K, Grallert H, Illig T, Ziegler AG, Bonifacio E. An interferon-induced helicase $(I F I H 1)$ gene polymorphism associates with different rates of progression from autoimmunity to type 1 diabetes. Diabetes. 2011; 60:685-90.

This study showed IFIH1 susceptibility alleles could triple rates of disease onset before 5 years of age (31\% vs $11 \%)$ drawing a link with reduced protection from environmental (viral) influences. 
45. Nielsen LB, Pörksen S, Andersen ML, Fredheim S, Svensson J, Hougaard P, Vanelli M, Åman J, Mortensen HB, Hansen L; Hvidoere Study Group on Childhood Diabetes. The PTPN22 C1858T gene variant is associated with proinsulin in new-onset type 1 diabetes. BMC Med Genet. 2011; 12:41.

**46. Howson JM, Rosinger S, Smyth DJ, Boehm BO; ADBW-END Study Group, Todd JA. Genetic analysis of adult-onset autoimmune diabetes. Diabetes. 2011; 60:2645-53.

A major study of the genetics of adult-onset T1D, finding that most of the genes associated with susceptibility in the adult-onset T1D cases were shared with juvenile onset T1D. The cases were thought to have a ower overall genetic load, which resulted in slower development of T1D.

*47. Brorsson C, Vaziri-Sani F, Bergholdt R, Eising S, Nilsson A, Svensson J, Lernmark Å, Pociot F; Danish Study Group of Childhood Diabetes. Correlations between islet autoantibody specificity and the SLC30A8 genotype with HLA-DQB1 and metabolic control in new onset type 1 diabetes. Autoimmunity. 2011; 44:107-14.

These researchers examined recently described autoantibodies for the ZnT8 Arg325Trp isoforms as well as potential interaction with a SNP associated with type 2 diabetes.

*48. Howson JM, Stevens H, Smyth DJ, Walker NM, Chandler KA, Bingley PJ, Todd JA. Evidence that HLA class I and II associations with type 1 diabetes, autoantibodies to GAD and autoantibodies to IA-2, are distinct. Diabetes. 2011; 60:2635-44.

The authors found differences between T1D cases in autoantibody production, depending on their genotypes of known HLA risk alleles, suggesting T1D subtypes.

**49. Cubas-Dueñas I, Cabrera-Rode E, Sarmiento L, Molina G, Fonseca M, Arranz C, Domínguez E, González P, Vera M, Díaz-Horta O. First-degree relatives of persons with type 1 diabetes: insulin resistance and enterovirus infection are associated with different patterns of islet cell autoimmunity. Acta Diabetol. 2011; DOI 10.1007/s00592-011-0297-6. 
This is an interesting report which points to physiological and environmental differences between T1D cases. The results suggest a basis for distinct disease mechanisms and hence different disease subtypes of T1D. 
Table 1. Genetic Variants Associated with Type 1 Diabetes

\begin{tabular}{|c|c|c|c|c|c|c|c|c|}
\hline Status & Gene/Region & Chr & $\begin{array}{c}\text { Position } \\
\text { (Mb) }\end{array}$ & SNP & Cited $\mathbf{P} *$ & Reference & Replication & Notes \\
\hline $\begin{array}{l}\text { Previously } \\
\text { Reported }\end{array}$ & $\begin{array}{l}\text { PGM1 } \\
\text { PTPN22 } \\
\text { RGS1 } \\
\text { IL10 } \\
\text { intergenic, } \\
\text { IL18RAP } \\
\text { intergenic } \\
\text { IFIH1 } \\
\text { CTLA4 } \\
\text { intergenic } \\
\text { HLA } \\
\text { BACH2 } \\
\text { C6orf173 } \\
\text { SKAP2 } \\
\text { COBL } \\
\text { GLIS3 } \\
\text { IL2RA } \\
\text { PRKCQ } \\
\text { RNLS } \\
\text { INS } \\
\text { CD69 } \\
\text { 12q13 } \\
\text { SH2B3 } \\
\text { ZFP36L1 } \\
\text { intergenic } \\
\text { CTSH }\end{array}$ & $\begin{array}{c}1 \\
1 \\
1 \\
1 \\
\\
2 \\
2 \\
2 \\
2 \\
4 \\
6 \\
6 \\
6 \\
7 \\
7 \\
9 \\
10 \\
10 \\
10 \\
11 \\
12 \\
12 \\
12 \\
14 \\
14 \\
15\end{array}$ & $\begin{array}{c}63.9 \\
114.2 \\
190.8 \\
205 \\
\\
12.6 \\
24.5 \\
162.9 \\
204.4 \\
25.7 \\
32.7 \\
91 \\
126.7 \\
26.9 \\
51 \\
4.3 \\
6.1 \\
6.4 \\
90 \\
2.1 \\
9.8 \\
\\
54.8 \\
111 \\
68.3 \\
97.6 \\
77\end{array}$ & $\begin{array}{r}r s 2269241 \\
r s 2476601 \\
r s 2816316 \\
r s 3024505 \\
r s 1534422 \\
r s 2165738 \\
r s 3747517 \\
r s 231727 \\
r s 10517086 \\
r s 9272346 \\
r s 11755527 \\
r s 9388489 \\
r s 7804356 \\
r s 4948088 \\
r s 7020673 \\
r s 12251307 \\
r s 947474 \\
r s 10509540 \\
r s 689 \\
r s 4763879 \\
r s 2292239 ; \\
r s 1701704 \\
r s 17696736 \\
r s 1465788 \\
r s 4900384 \\
r s 3825932\end{array}$ & $\begin{array}{r}6.4 \\
39.9 \\
3.5 \\
8.7 \\
\\
5.7 \\
5.4 \\
3.6 \\
10.1 \\
9.3 \\
218.3 \\
11.3 \\
12.4 \\
8.3 \\
7.4 \\
11.3 \\
5.6 \\
8.4 \\
27.9 \\
47.4 \\
10.7 \\
\\
15.5 \\
17.2 \\
11.7 \\
8.4 \\
14.5\end{array}$ & $\begin{array}{r}4 \\
1,2,4 \\
4 \\
4 \\
4 \\
4 \\
4 \\
4 \\
4 \\
1,2 \\
4 \\
4 \\
4 \\
4 \\
4 \\
4 \\
4 \\
4 \\
4 \\
2 \\
4 \\
4 \\
4 \\
4 \\
4 \\
4\end{array}$ & $\begin{array}{r}7,8,9 \\
7,8 \\
7,8 \\
\text { no }(8) \\
7,8,9 \\
7,8,9 \\
7,8 \\
7 \\
7,8 \\
7,8 \\
7,8,9 \\
\text { no }(8) \\
7,8,9 \\
7,8,10 \\
7,8 \\
7,8,9 \\
7,8,9 \\
7,8 \\
7,8 \\
11,12 \\
13,14 \\
7,8 \\
7,8 \\
7,8,9\end{array}$ & 1 \\
\hline
\end{tabular}




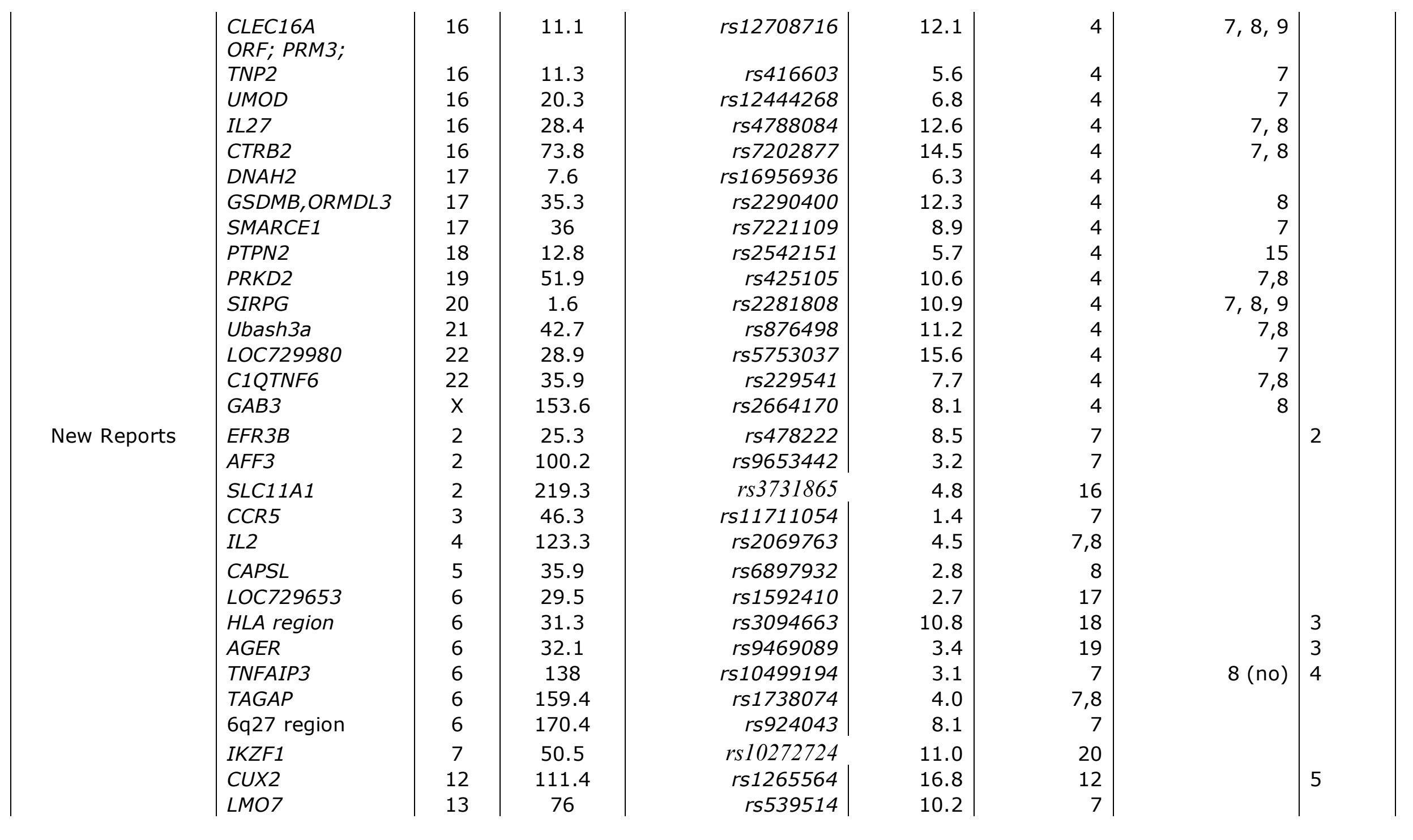




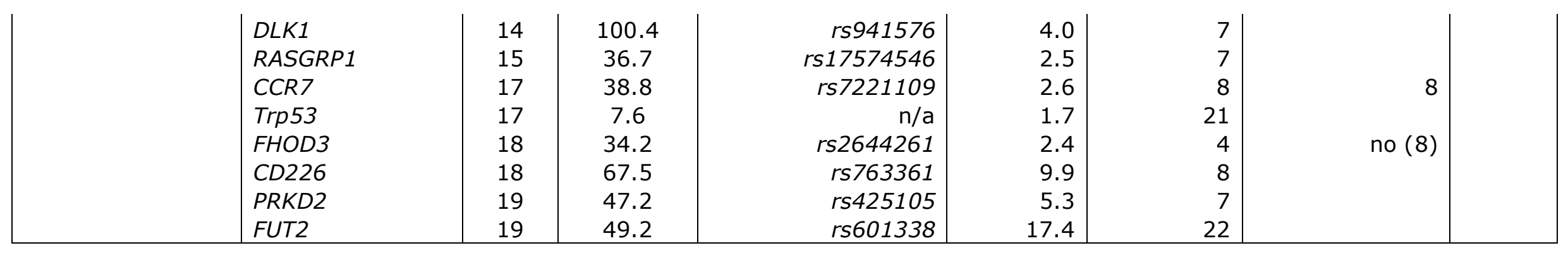

\section{Notes:}

* For clarity, $\mathrm{P}$ values are expressed as negative logarithms (ie $-\log \mathrm{P})$.

$1 \quad$ KIF5A at $12 \mathrm{q} 13$ was not replicated in ref 8

2 The associated LD region is $\sim 800 \mathrm{~kb}$ and has several genes; this region is also near the associated SNP rs 2165738 [4]

3 P values shown are conditional on appropriate HLA DR/DQ genotypes

4 Ref 8 found evidence for association at this locus, but the statistical model was not consistent with the first report.

6 Overlaps with and provides a stronger signal for the $S H 2 B 3$ region 